\title{
Your Death Can Brighten Up Another's Life (World Organ Donation Day Guest Comment)
}

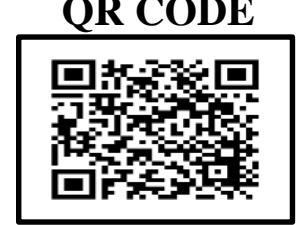

Dr. Gyanendra Mishra

The Inconsolable grief of losing one's dear one cannot be expressed in words. However, rising up from the grief and making the decision to donate the organs of the deceased is a noble cause indeed, and goes beyond the call of humanity as it gives the opportunity to an otherwise ailing person to live a healthy and normal life. International Organ donation day is celebrated on the 13th of August every year, and I thank the editorial team of the International Healthcare Research Journal (IHRJ) for proving me an opportunity to shed light on this day of immense importance.

As the name suggests: the main aim to celebrate this day is loud and clear: To promote organ donation among those, who are in need of them and to also educate people regarding this noble deed.1 In layman terms, the process where an organ is transferred from the body of the one who is giving the organ (donor) to the one who needs the organ (recipient) is termed as organ donation. The donor can either be living or deceased. Globally, there are almost millions of people in the need of organ donation. The united nations state that Every 10 minutes, a person is added to the a transplant waiting list; And on an average, 20 people die while waiting for a transplant.2 Globally and in India, the most common organ that is donated is the kidney. In India itself, Approximately 5 lakh people die awaiting for an organ donation, and out of 1,50,00o people waiting a kidney transplant, only 50,000 get one. Sadly, the PMP (Persons as organ donor per Million Population is just 0.08), and is extremely low as compared to other countries. The world's largest organ donor is Spain since the past 24 years, and in the year 2015, it beat its own record with 39.7 donors per million population by performing 4,769 transplants.3 Hence, massive pledges are required from people to save lives by donating their organs upon their death (due to both natural causes or unnatural causes like trauma, accidents etc. and the criteria for donating organs is based on strict medical criteria).

There is no age limit to be an organ donor. Moreover, one does not actually need to die for donating an organ. For example a live kidney donation can be made, and the person donating one kidney can live absolutely fine with one kidney.

Another interesting fact is that Iran is the only country that allows organs to be bought and sold legally, but to place restrictions on the same, foreigners are not allowed to buys organs of Iranian citizens as the market is contained within the country.

I hope I have shed enough light on the importance of organ donation. I urge people to pledge to donate their organs to someone in need. Let your death be the light of another's hope to live a normal, healthy life. This is the least we can do for the benefit of humanity.

\section{REFERENCES}

1. https://www.ndtv.com/health/world-organdonation-day-2018-things-no-one-told-you-aboutorgan-donation-1899472

2. https://unos.org/data/

3. https://sites.ndtv.com/moretogive/spain-worldslargest-organ-donor-can-india-follow-suit-1044/

Cite this article as:

Mishra G. Your Death Can Brighten Up Another's Life. Int

Healthcare Res J 2018;2(5):104 . doi: 10.26440/IHRJ/02_05/186

Author Details \& Corresponding Address:

Dr. Gyanendra Mishra

Medical Officer Dental

Ministry of Health Jharkhand,

Editorial Board Member, IHRJ

For article enquiry/author contact details, e-mail at: manuscriptenquiry.ihrj@gmail.com 